review his work almost indefinitely until he is entirely satisfied with the situation he has created, and is not annoyed by the hemorrhage. The only technical difficulty connected with the procedure lies in the proper heating of the cauteries under water, a thing which, however, is entirely feasible and has bcen done many times before. It will require some care in their manufacture and then considerable patience on the part of the surgeon to determine just how much current is necessary to heat them without the danger of fusing them. They must

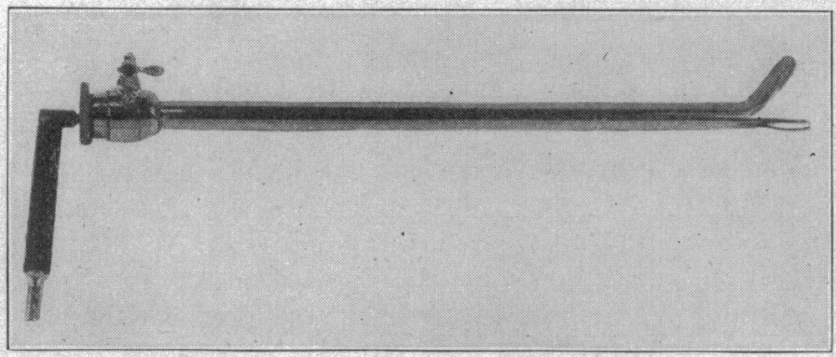

Fig. 3.-Braasch cystoscope with cautery knife in position.

of course never be exposed to the current while in the air or they will fuse instantly. At best the surgeon must expect to burn out a knife occasionally and should therefore always take several of these cauteries with him to every operation. Finally, the pleasure to be derived from raking out an offending projection through the eystoscope under the direct control of the eye, together with the ease and simplicity with which this can be accomplished, will amply repay him for all his trouble.

600 Carleton Building.

\section{SOME NEW CAMERAS FOR LABORATORY USE *}

Louis B. Wilson, M.D., Rochester, MinN.

I have recently completed two cameras for laboratory use, and in describing them also include two others which have been in use for some time previously.

\section{CAMERA FOR USE WITH PROCTOSCOPE}

This camera (Fig. I) consists of a cylindrical barrel (A) to the front end of which is attached a rapid, short-focus, photographic lens $(B)$ and to the other end of which is attached a simple photographic shutter $(C)$ and small metal receiver $(D)$ for taking a plate-holder $(E)$ which carries an ordinary photographic plate $4.5 \mathrm{by} 6 \mathrm{~cm}$. in diameter.

In use, when a desirable field is found through the directvision proctoscope $(F)$, the camera is inserted with the shutter closed and set for time exposure and the dark slide of the plate-holder drawn. The patient's buttocks are steadied, the shutter snapped and an exposure of from 2 to 5 seconds given. The shutter is then closed and the camera withdrawn from the proctoscope. The operation should require not more than twenty seconds, and interferes but slightly with the ordinary course of a proctoscopic examination. The resulting pictures

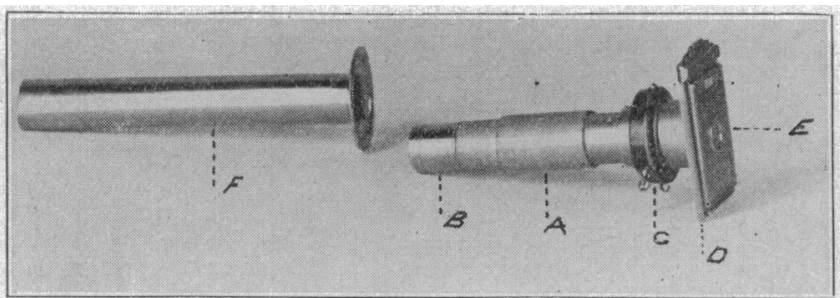

Fig. 1.-Camela for use with proctoscope; $A$, tube; $B$, lens; $C$, shitter; $D$, receiver ; $E$, plate-holder ; $F$, proctoscope.

are circular and $1 \frac{118}{8}$ inch in diameter. The chief difficulty encountered is in maintaining the patient in a fixed position for the few seconds necessary to make an exposure.

\section{MINIATURE CAMERA FOR PHOTOMICROGRAPHY}

Laboratory workers have for a long time experienced great inconvenience in having to carry a microscopic slide from the

* From the Mayo Clinis. microscope which they ordinarily use to one set up and adjusted for photography. A number of eameras have been devised to obviate this difficulty. With but two exceptions, these have all required the use of a large heavy plate on which the microscope rests at ail times or to which it must be transferred after the desired field is found. Of the two exceptions, one is a camera which fits directly on the drawtube of the microscope, weighs $685 \mathrm{gm}$. ( 23 ounces) and uses a plate of a size difficult to obtain in America. The other is a camera which has a very heavy base, and while the whole apparatus may be moved up to the microscope, yet has no means of rapidy centering the two. The miniature camera here described and the larger portable camera to be described next both get rid of the inconvenience of the heavy sole-plate, and yet work with simplicity, speed and accuracy.

The miniature camera (Fig. 2 ) consists of a pyramidal aluminum box $(A)$ bearing at one end a shutter $(B)$ with a light-tight connecting sleeve $(C)$ and at the other end a receiver $(D)$ which takes a plate-holder $(E)$ carrying a plate of the ordinary block-note size, 4.5 by $6 \mathrm{~cm}$. The whole apparatus is 9 inches long and welghs, complete as it goes on the microscope, only a trifle over 7 ounces. In use, when a desirable field has been found in the microscope, the camera is slipped on the microscope, to which it fits securely by

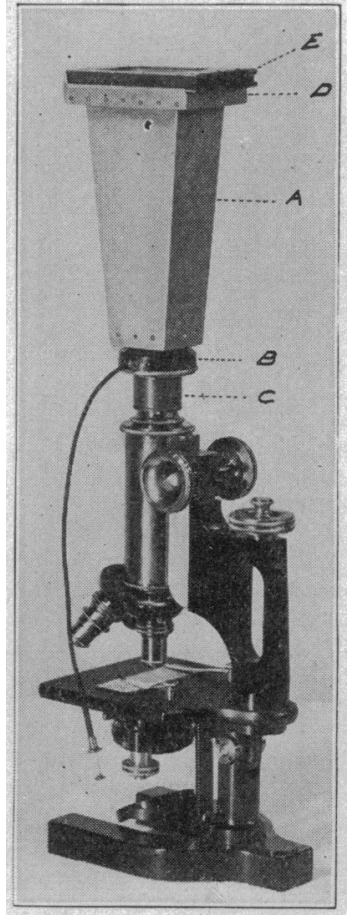

Fig. 2.- Miniature cam era for photomicrography:
$A$, box ; $B$, shutter; $C$, lighttight sleeve: $D$, receiver $E$, plate-holder.

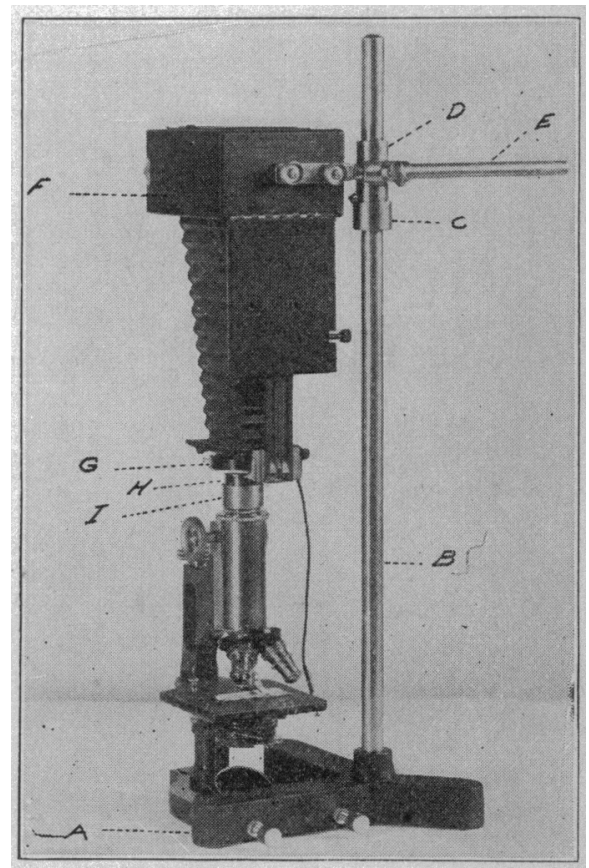

Fig. 3.- Poltable stand and camera for photomicrography; $A$, base ; $B$ support; $C$, collar; $D$, reducing clamp; $E$, arm ; $F$, cámera ; $Q$, shutter $; H$, and $I$, sleeve. means of a sleeve that remains permanently on the drawtube. The camera is placed in position with the dark slide drawn and the shutter set for a time exposure and closed. The focus is then adjusted an amount previously determined by the fine adjustment screw, the shutter opened and the exposure made. The shutter is then closed and the camera removed from the micrcscope. The whole operation may be done without in the least jarring the microscope. Aside from the time of the exposure, which of course varies with the kind of light used and the magnification, the entire process requires less than a minute. This litt!e camera gives excellent results, though its field of usefulness is, of course, limited by the small size of the plate and by the short range $o_{-}^{s}$ magnification resulting from its short, fixed extension.

\section{MEDIUM-SIZED PORTABLE STAND AND CAMERA FOR} PHOTOMICROGRAPHY

This stand and camera (Fig. 3) have been devised to get rid of the inconvenience of the sole-plate or other special stand to which the microscope has hitherto been attached when used for photomicrography. The new features in it are: (I) a tripod base ( $A$ ) which can be adjusted accurately by 
set-screws to any microscope with the ordinary horse-shoe base so that the instrument, while not attached in any manner to the microscope, can be brought instantly into accurate alignment with it; $(2)$ a supporting rod $(B)$ carrying a collar $(C)$ and clamp $(D)$, the latter of which is specially constructed for holding a round horizontal arm $(E)$ in a manner that will permit its being turned at any angle and yet held with great firmness without turning; and $(3)$ the camera $(F)$ carried by tle horizontal arm, by means of which it may be adjusted to any position from vertical to horizontal or tipped at any desired angle.

The camera itself takes the ordinary plate-holder for $31 / 4$ by $41 / 1$ plates, but is heavily reinforced in its working parts and has an unusualiy long bellows. A shutter $(G)$ and light-tight sleeve $(H)$ are attached to the front board. In use, the microscope to which the camera has been previously adjusted and to which is permanently affixed only a small inconspicuous part $(I)$ of the light-tight sleeve may be used anywhere on a fairly level table. When a desirable field is found, the entire stand and camera are moved into position so that the studs and set-screws are in contact with the base of the microscope, when it will be found that the two instru-

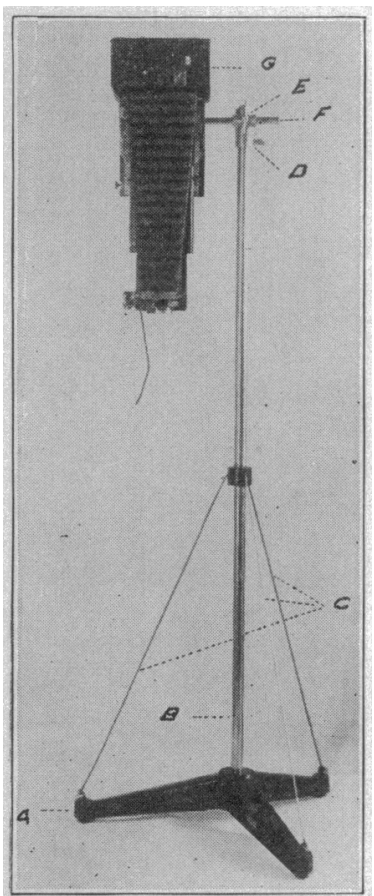

Fig. "4.-Large stand and camera for specimen and general laboratory photog raphy; $A$, base; $B$, support
rcd; $C$, guy rods $: D$, collar $\underset{E,}{\mathrm{rcd} ;} \boldsymbol{C}$, guy rods ; $D$, collar; arm $: G$, camera. inents are in exact alignment. The readjustment of the focus may be made ordinarily with low powers by the fine adjustment screw, or, if necessary, with high powers, by refocusing on the ground glass. The subsequent steps of taking the photograph are those ordinarily employed.

The camera may be rotated on the support-rod at will and brought again into exact alignment by means of two stopstuds-one on the collar and one on the clamp-which engage with each other. It may be used with the microscope in the horizontal position or inclined at any angle, though the instantaneous alignment is obtained only when the instrument is in the vertical position.

Photographic lenses may be added to the shutter and the camera very conveniently used for photography of specimens and apparatus, or for making portraits, ete., while it is stil attached to the stand. Or the camera may be detached entirely from the stand and then forms a high-class folding pocket camera suitable for plates or film-pack. For use with extra long-focus lenses, I have had this camera built with a 16-inch extension which is obtained by means of a supplementary bed.

IV. LARGe STAND AND CaMERA For PORTRAITs, GRoss SPECIMENS AND GENERAL LABORATORY WORK

Six years aro Andrews and I built and described (Jour. Med. Research, 1908, xvii, 487) a large stand and camera for photographing pathologic specimens submerged. This apparatus has proved to be thoroughly satisfactory in our hands, but there is a demand for a more portable and withal a less expensive machine to serve the same purpose. I have therefore devised the stand and camera shown in Figure 4. This apparatus which is well adapted for taking portraits of patients, photographs of gross specimens or operations and for general photographic laboratory work, consists of a heavy tripod base $(A)$ into which is screwed a heavy support-rod $(B)$ 5 feet high, which is reinforced and made more rigid by three small guy-rods $(C)$ running from a collar near its middle point to the ends of the feet of the tripod. On the supportrod are carried a collar $(D)$ and right-angle clamp $(E)$ which is specially bored to hold securely at any angle a round arm $(F)$ with a forked end to which is attached an ordinary long-extension 5 by 7 folding box camera $(G)$. The eamera may 'be used in the vertical position, as when photographing specimens under water, horizontally as for portrait work, or inclined at any angle as in taking photographs of operations, apparatus, etc. Hardened steel domes are inserted at the bearing points of the tripod in lieu of the usually unsteady casters. The whole apparatus is portable, light, simple in construction and extremely rigid, while its cost is very low.

\section{A MEANS OF FACILITATING THE APPLICATION OF LEG-DRESSINGS}

John Staige Davis, M.D., Baltimore

Instructor in Surgery, Johns Hopkins Lniversity Medical Department

An uncomfortable or awkward position hinders efficient work in any occupation, including surgical manipulations. In the outpatient department of every large surgical service many leg cases are dressed. Such dressings are often avoided, partly because of the physical discomfort necessary in applying these dressings under ordinary conditions.

The heel-rest usually supplied for this work is slightly higher than the seat of an ordinary chair, and unless the dresser sits down to apply the bandage, he is compelled to bend over and assume a very tiring position, which is a matter of considerable moment where there are a number of these dressings.

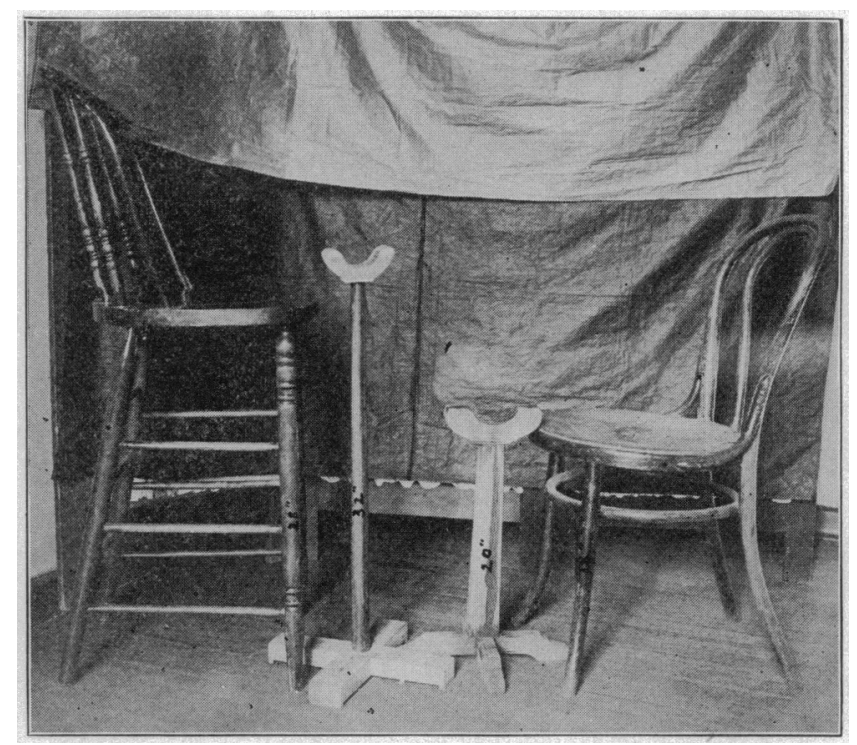

The high chair and heel-rest compared with those ordinarlly used.

In a busy clinic it is obviously impractieable for each dresser to have a seat for this purpose, and consequently a considerable amount of energy is unnecessarily expended. In order to avoid this useless fatigue and to accelerate the work, it occurred to me that higher chairs and correspondingly higher heel-rests might be of advantage. A number of these chairs with seats 28 inches above the floor, and heel-rests 32 inches high, were tried in one of the rooms of the outpatient department, and their use has greatly facilitated the application of leg-dressings.

Dressings on other parts of the body are also made easier by the use of these chairs, thus sparing the surgeon unnecessary discomfort. Should it be desirable to have the leg elevated before applying the dressing, the high heel-rest may be used while the patient sits on a chair of ordinary height

These simple and inexpensive modifications in the equipment of a surgical dressing-room seemed worth while reporting, as I have found them most satisfactory.

Women in Medicine.-We are prone in the modern time to think that our generation is the first to offer to women any facilities or opportunities for education in medicine. We are prone, however, just in the same way, to consider that a number of things that we are doing are now being done for the first time. As a matter of fact, it is extremely diffcult to find any important movement or occupation that is not merely a repetition of a previous interest of mankind.Walsh: Makers of Medicine. 